\title{
EVALUASI PENGGUNAAN DUA BUAH MINI CHAMBER PADA KALIBRASI TERMOHIGROMETER
}

\author{
Evaluate of Two Mini Chamber on Thermohygrometer Calibration
}

\author{
Melati Azizka Fajria', Arfan Sindhu Tistomo² dan Dwi Larassati ${ }^{1}$ \\ ${ }^{1}$ Pusat Riset dan Pengembangan Sumber Daya Manusia - BSN, Kompleks Puspiptek Gedung 430 Setu \\ Tangerang Selatan, Banten, Indonesia \\ ${ }^{2}$ Direktorat SNSU - BSN , Kompleks Puspiptek Gedung 420 Setu, Tangerang Selatan, Banten, Indonesia \\ e-mail: melati@bsn.go.id
}

\begin{abstract}
Abstrak
Beberapa peralatan kalibrasi dan pengujian memiliki sensitifitas yang tinggi terhadap perubahan suhu dan kelembapan lingkungan. Oleh karena itu peralatan penunjang yang digunakan untuk memantau suhu dan kelembapan harus memiliki ketelitian yang mencukupi kebutuhan pengukuran dan juga harus menunjukkan nilai yang benar. Salah satu upaya menjaga peralatan menunjukkan nilai yang benar adalah dengan proses kalibrasi. Pada proses kalibrasi termohigrometer, mini chamber digunakan sebagai salah satu upaya untuk meningkatkan nilai ketidakpastian yang ditawarkan dan tingkat keakurasian dari DUT yang dikalibrasi. Perbedaan signifikan nilai ketidakseragaman suhu dari kedua chamber yang terjadi ketika dilakukan pengukuran pada suhu tinggi. Pada suhu $50{ }^{\circ} \mathrm{C}$ didapati perbedaan ketidakseragaman suhu dari chamber sebesar $0,3{ }^{\circ} \mathrm{C}$. Evaluasi terhadap kedua mini chamber dilakukan dengan melakukan perhitungan statistik menggunakan En Number, didapatkan nilai $\left|E_{n}\right|=0,9$. Sehingga dapat disimpulkan bahwa kedua mini chamber dapat digunakan untuk melakukan pengukuran kalibrasi. Namun demikian, square mini chamber menawarkan tingkat presisi dan akurasi untuk DUT yang lebih baik dibandingkan cylinder mini chamber. Dibandingkan dengan cylinder mini chamber, tingkat keakurasian DUT ketika dikalibrasi menggunakan square mini chamber memberikan nilai $\pm 30 \%$ lebih akurat terhadap standar. Nilai tersebut dapat memberikan gambaran bahwa nilai yang ditunjukkan oleh DUT berupa probe termohigrometer lebih mendekati nilai yang ditunjukkan oleh standar.
\end{abstract}

Kata kunci: kalibrasi, termohigrometer, mini chamber

\begin{abstract}
Most calibration and testing have a high sensitivity to tempearature change and ambient relative humidity. Therefore the equipment is used to monitor temperature and humidity must have sufficient accuracy and also show the correct value. One of effort to keep the equipment giving the correct value is the calibration process. in calibration procces; mini chamber is used as a method to increase the uncertainty value and the accuracy of the calibrated thermohygrometer. At high temperatures, found a significant difference of uniformity in the chamber. There is $0.3{ }^{\circ} \mathrm{C}$ difference in uniformity temperature of the chamber at $50{ }^{\circ} \mathrm{C}$ setpoint. Both of mini chamber is evaluated using En Number and is got the En Number value is $\left|E_{n}\right|=0,9$. So it can be concluded that two mini chambers can be used to carry out calibration measurements. However, the square mini chamber offers a better level of precision and accuracy for DUT than the cylinder mini chamber.It is $\pm 30 \%$ more accurate. This value can give an idea that the value shown by the DUT in this case is a thermohigrometer probe is closer to the value indicated by the standard.
\end{abstract}

Kata kunci: calibration, thermohygrometer, mini chamber

\section{PENDAHULUAN}

Kebutuhan pemantauan suhu ruang pada berbagai laboratorium pengujian dan kalibrasi merupakan salah satu hal yang memiliki peranan penting. Beberapa peralatan kalibrasi dan pengujian memiliki sensitifitas yang tinggi terhadap perubahan suhu dan kelembapan lingkungan. Perubahan tersebut tentu saja dapat mempengaruhi peforma dari alat sehingga dapat mempengaruhi hasil dari pengujian ataupun kalibrasi.
Sebagai contoh peralatan yang sangat sensitif terhadap perubahan suhu adalah peralatan pada laboratorium panjang. Koefisien ekspansi termal pada berbagai material bergantung pada suhu absolut dari meterial. (Doiron \& Beers, 1995). Pada pengukuran gauge block misalnya, kondisi suhu selama kalibrasi gauge block dapat berpengaruh pada pertambahan panjang. Gauge block sepanjang 20 inci yang dikalibrasi pada suhu $21^{\circ} \mathrm{C}$ dapat bertambah panjang sebesar 0,0002 inci. (Salsbury, 2018). Pengaruh suhu dapat 
menyebabkan perubahan yang ekstrim ketika melakukan kalibrasi long gauge block. Semakin besar kondisi suhu selama pengukuran maka akan semakin besar pula ekspansi thermal yang terjadi pada gauge block yang dapat mempengaruhi hasil kalibrasi. Oleh karena itu untuk meminimalisir terjadinya perubahan panjang dari gauge block selama kalibrasi berlangsung, laboratorium SNSU panjang BSN memberikan syarat kondisi ruangan sebesar 20 $\pm 0,5^{\circ} \mathrm{C}$.

Selain itu, kondisi suhu dan kelembapan juga berpengaruh pada pengukuran akustik. Mengacu pada ICE 60942:2017, kondisi ruang yang ditetapkan untuk proses kalibrasi sound calibration berada pada kondisi ruang $20 \sim 26^{\circ} \mathrm{C}$ dan $40 \sim 65 \% \mathrm{RH}$ (IEC, 2017). Kondisi tersebut harus terpenuhi selama proses kalibrasi berlangsung, apabila kondisi ruangan yang dipersyaratkan tidak tercapai, maka proses kalibrasi tidak dapat berlangsung.

Pada kegiatan pengujian, kondisi suhu berpengaruh terhadap uji kekerasan dan kekuatan tarik dari sturktur mikro baja K-460. Penelitian yang dilakukan oleh Haryadi menyimpulkan bahwa kekerasan dan kekuatan tarik dari besi K-460 berbanding terbalik dengan kenaikan suhu. Semakin tinggi suhu yang diberikan maka, kekerasan dan kekuatan tarikan akan semakin menurun (Haryadi, 2006) .

Dengan persyaratan kondisi seperti yang disebut diatas, maka dapat diambil kesimpulan bahwa besaran suhu dapat mempengaruhi kondisi peralatan dan bahan uji hingga dapat memberikan dampak yang signifikan pada komponen ketidakpastian serta hasil uji bahan. Salah satu upaya memantau persyaratan kondisi lingkungan tersebut adalah dengan menggunakan sensor suhu. Oleh karena itu, sensor suhu yang digunakan untuk memantau kondisi lingkungan harus memiliki ketelitian yang mencukupi kebutuhan pengukuran, Selain itu sensor juga harus menunjukkan nilai yang benar. Salah satu cara untuk menjamin bahwa alat ukur menunjukkan nilai benar adalah dengan cara kalibrasi.

Kalibrasi peralatan ukur merupakan salah satu tugas dan fungsi direktorat SNSU BSN dalam penjagaan ketertelusuran peralatan pengukuran ke SI. Salah satu peralatan pengukuran suhu dan kelembapan yang memiliki ketelitian yang cukup tinggi dan banyak digunakan oleh laboratorium kalibrasi sebagai transfer standar untuk kalibrasi termohigrometer kelas industry adalah 1620A DewK termohigrometer. Termohigrometer (DewK termohigrometer tipe S) memiliki rentang area kerja yang cukup besar yaitu ada pada range ukur $0 \sim 50{ }^{\circ} \mathrm{C}$ untuk suhu dan $0 \sim 100 \% \mathrm{RH}$ untuk kelembapan relatif. Sedangkan spesifikasi untuk akurasi sensor suhu sebesar $\pm 0.25^{\circ} \mathrm{C}$ pada kondisi $15 \sim 35{ }^{\circ} \mathrm{C}$ dan $\pm 2 \% \mathrm{RH}$ pada kondisi $20 \sim 70 \% \mathrm{RH}$ untuk akurasi kelembapan relatif (Fluke, 2011).

Salah satu upaya dalam menjamin ketepatan waktu pelayanan kalibrasi adalah dengan proses kalibrasi yang stimultan, yaitu mengkalibrasi beberapa sensor dalam satu kali loop pengukuran. Cara ini dimungkinkan dalam proses kalibrasi, namun terdapat beberapa faktor yang harus diperhatikan selama proses kalibrasi berlangsung agar hasil yang didapatkan tetap dapat dipertanggung jawabkan nilai kebenarannya. Berapa hal yang menjadi tantangan ketika proses kalibrasi dilakukan secara stimultan antara lain ketidakseragaman suhu dari chamber, mutual self-heating dari sensor, aliran udara di sekitar sensor selama proses kalibrasi berlangsung dan kondisi dari chamber (Walker \& Cordner, 2006).

Walker \& Cordner mengatakan bahwa untuk dapat menghasilkan hasil kalibrasi yang baik tanpa terpengaruh dari self-heating dan mutual heating dari Device Under Test (DUT) selama proses kalibrasi merupakan hal yang sulit. Ketika proses kalibrasi berlangsung dan DUT yang dikalibrasi disatukan dan ditempatkan secara bersamaan dalam satu ruangan, maka panas dari masing-masing DUT akan mempengaruhi DUT lainnya. Hal tersebut tentu akan berpengaruh pada nilai yang terukur oleh DUT selama proses kalibrasi. Dengan kondisi tersebut DUT akan mengukur nilai yang lebih tinggi dibanding nilai aktual dari yang terkondisikan di dalam chamber.

Yang menjadi konsentrasi dalam penulisan makalah ini adalah pengembangan teknik kalibrasi termohigrometer untuk mendapatkan nilai akurasi dan ketidakpastian yang lebih baik dibandingkan dengan teknik kalibrasi yang saat ini sudah berjalan. Salah satu cara untuk mendapatkan kualitas hasil kalibrasi yang lebih baik adalah dengan membandingkan hasil kalibrasi dengan dua mini chamber yang berbeda. Sehingga dapat diketahui apakah kondisi peletakan DUT menjadi hal yang perlu dievaluasi dalam proses kalibrasi sehingga dapat memberikan hasil kalibrasi yang lebih baik.

Pada proses kalibrasi yang sudah
berjalan, menggunakan cylinder mini chamber dengan volume $1500 \mathrm{ml}$. Hasil kalibrasi tersebut kemudian akan dibandingkan dengan mini chamber lain berbentuk kotak (square mini chamber) dengan volume $850 \mathrm{ml}$. Data yang didapat dari kedua pengukuran tersebut 
kemudian akan divalidasi untuk menjaga kualitas mutu pengukuran kalibrasi pada lingkup higrometri untuk memenuhi standar yang ditetapkan dalam ISO/IEC 17025.

\section{TINJAUAN PUSTAKA}

\subsection{Transfer Standar Humidity}

Pemilihan transfer standar humidity untuk kalibrasi termohigrometer harus memenuhi beberapa persyaratan, diantaranya alat yang digunakan sebagai standar harus memiliki tingkat kestabilan dan keakurasian yang lebih tinggi dibandingkan dengan DUT yang akan dikalibrasi. Salah satu tipe transfer standar humidity yang biasa digunakan oleh laboratorium kalibrasi adalah capacitive $R H$ hygrometers. Kelebihan dari peralatan jenis ini adalah harga yang jauh lebih terjangkau bila dibandingkan dengan standar humidity berupa chilled mirror hygrometer dengan perawatan yang lebih mudah (Heinonen, 2018). Oleh karena itu transfer standar humidity jenis ini lebih banyak digunakan sebagai referensi untuk kalibrasi thermohigrometer pada beberapa laboratorium kalibrasi di Indonesia, termasuk kalibrasi termohigrometer untuk kelas industri pada Subdirektorat SNSU suhu, BSN.

\subsection{Two-Pressure Humidity Generator}

Standar primer yang digunakan pada kalibrasi humidity adalah two-pressure humidity generator. Sistem operasi digambarkan pada gambar 1.

Metode dasar dari two-pressure generator adalah menjenuhkan udara dari tekanan tinggi ke tekanan lebih rendah (Hasegawa \& Little, 1977). Pada prosesnya, udara yang masuk ke dalam generator diatur alirannya sebelum masuk ke saturator. Di dalam saturator uap air dijenuhkan. Uap air jenuh dari saturator kemudian masuk ke dalam expansion valve, kemudian udara jenuh bertekanan tinggi tersebut mengalami reduksi tekanan menjadi tekanan ruang secara isotermal (El-Galil \& Mahmoud, 2016; Tistomo, 2009). Selama proses berlangsung suhu gas dijaga konstan, sehingga kelembapan chamber dapat ditentukan dari pengukuran tekanan jenuh dan tekanan chamber serta suhu jenuh dan suhu chamber (Thunder Scientific Corporation, 2007).

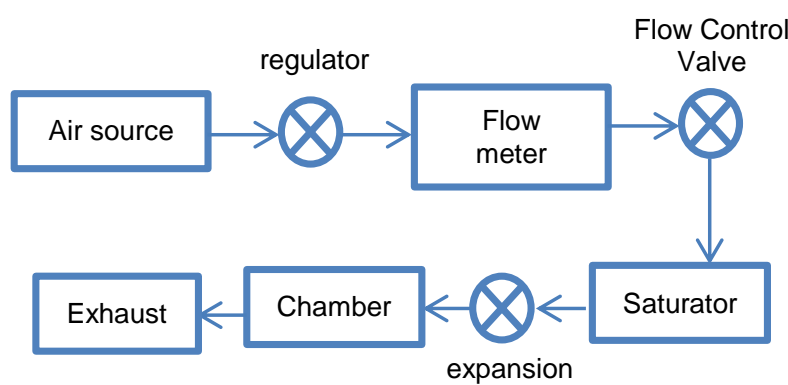

Gambar 1. Sistem operasi two-pressure humidity generator (Thunder Scientific, 2018)

Perhitungan kelembapan relatif mengikuti persamaan (1)

$\% R H=\frac{f\left(P_{S}, T_{S}\right) \cdot e_{S}\left(T_{S}\right)}{f\left(P_{c}, T_{S}\right) \cdot e_{S}\left(T_{c}\right)} \cdot \frac{P_{c}}{P_{S}} \cdot \eta_{s}$

Dimana :

$P_{c}$ adalah tekanan chamber

$P_{s}$ adalah tekanan saturator

$T_{c}$ adalah suhu chamber

$T_{s}$ adalah suhu saturator

$e_{s}$ adalah tekanan uap air jenuh

$f$ adalah enhancement factor

$\eta_{s}$ adalah nilai efisiensi saturator

Untuk menentukan besarnya nilai tekanan uap air jenuh dan enhancement factor, digunakan formula waxler dengan nilai koefisien yang dikembangkan oleh Hardy. (Hardy, ITS-90 Formulations for Vapor Pressure, Frost Point Temperature, Dew Point Temperature and Endachement Factors in the Range - 100 to + 100., 1998)

\subsection{Mini Chamber}

Chamber utama pada two-pressure humidity generator memiliki spesifikasi dimensi $381 \mathrm{~mm} \times$ $381 \mathrm{~mm} \times 305 \mathrm{~mm}$ dengan keseragaman dari suhu sebesar $\pm 0,1^{\circ} \mathrm{C}$. Nilai tersebut dapat berkontribusi pada perhitungan ketidakpastian pengukuran kelembapan relative sebesar $\pm 0,07$ $\% \mathrm{RH}$ pada suhu $20^{\circ} \mathrm{C}$ dan $\pm 0,1 \% \mathrm{RH}$ pada suhu $27^{\circ} \mathrm{C}$ (Tistomo, Achmadi, \& Rifai, 2014). Salah satu upaya untuk meningkatkan akurasi pengukuran adalah dengan memperkecil volume kerja dari chamber. Hal tersebut bertujuan untuk mendapatkan nilai keseragaman suhu yang lebih baik. Tistomo, Achmadi, \& Rifai (2014) mendapati terdapat pengaruh dari penggunaan mini chamber terhadap besarnya keseragaman 
suhu. Besarnya keseragaman suhu yang didapatkan setelah menggunakan mini chamber yaitu sebesar $\pm 0,04{ }^{\circ} \mathrm{C}$.

Pengukuran keseragaman suhu di dalam mini chamber menggunakan minimal dua buah RTD (Moris, 1992). RTD yang berasal dari humidity generator dan RTD tambahan lainnya. Temperature di dalam mini chamber dapat dihitung dengan merata-ratakan nilai keluaran dari kedua RTD.

$t_{c h}=\frac{\overline{t_{1}}+\overline{t_{2}}}{2}$

Dimana $\overline{t_{1}}$ adalah suhu rata-rata RTD bawaan humidity generator dan $\overline{t_{2}}$ suhu rata-rata dari RTD tambahan. Perhitungan ketidakpastian suhu aktual dari mini chamber mengikuti persamaan berikut

$u_{t_{c h}}=\sqrt{\left(\frac{1}{2} u_{t 1}\right)^{2}}+\sqrt{\left(\frac{1}{2} u_{t 2}\right)^{2}}$

$u_{t 1}$ merupakan ketidakpastian dari $t_{1}$ dan $u_{t 2}$ merupakan ketidakpastian dari $t_{2}$.

Keseragaman suhu didalam chamber dapat mengikuti persamaan (Hardy, 1998):

uniformity $^{2}=M a x D e v^{2}+u t_{c h}{ }^{2}$

\subsection{Sumber Ketidakpastian}

Perhitungan ketidakpastian two pressure humidity generator menggunakan acuan yang telah dikembangkan oleh NIST Guideline 1297 (Taylor \& Kuyyat, 1994; Wexler \& Daniels, 1952; Hasegawa \& Little, 1977). Pada kalibrasi termohigrometer, sumber ketidakpastian secara garis besar dibagi menjadi dua, yaitu berasal dari standar humidity generator dan DUT. Dari standar humidity generator yang berkontribusi pada komponen ketidakpastian antara lain (Rifai \& Tistomo, 2012) :

1. Ketidakpastian rasio tekanan $\left(\frac{P_{c}}{P_{S}}\right)$

2. Ketidakpastian rasio tekanan uap air jenuh $\left(\frac{E_{S}}{E_{c}}\right)$

3. Ketidakpastian rasio enhancement factor $\left(\frac{f_{s}}{f_{c}}\right)$

4. Ketidakpastian efisiensi saturator

5. Ketidakpastian gradien tekanan uap air

6. Estimasi sumber ketidakpastian lain (0,3 $\% \mathrm{RH}$ )

Sedangkan komponen ketidakpastian yang berasal dari DUT terdiri dari resolusi, stabilitas, linearitas, dan fitted correction dari DUT.

\section{METODE PENELITIAN}

Termohigrometer DewK tipe $S$ dikalibrasi menggunakan two-pressure humidity generator merk thunder scientific 2500. Termohigrometer dikalibrasi suhu dan kelembapan pada rentang ukur suhu $18 \sim 22^{\circ} \mathrm{C}$ dan rentang ukur kelembapan 45 65 \%RH. Sebagai perbandingan, jumlah maksimal DUT yang dikalibrasi dalam satu kali proses disamakan dengan metode kalibrasi yang telah berjalan yaitu sebanyak 4 buah.

Selain itu dilakukan pengukuran pengaruh suhu terhadap probe dengan dilakukan pengukuran suhu pada titik ukur $5^{\circ} \mathrm{C}, 27^{\circ} \mathrm{C}$, dan $50{ }^{\circ} \mathrm{C}$. Data suhu dari probe diambil selama 30 menit.

Mini chamber berbentuk silinder dan terbuka (cylinder mini chamber) dengan besar volume $1500 \mathrm{~m} \ell$ dibandingkan dengan mini chamber berbentuk kotak tertutup (square mini chamber). Mini chamber tersebut memiliki volume yang lebih kecil dibandingkan dengan mini chamber sebelumnya yaitu $850 \mathrm{~m} \ell$. Gambar 2 adalah penggunaan mini chamber di dalam chamber utama two-pressure humidity generator.

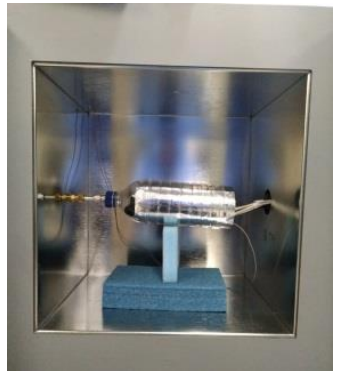

(a)

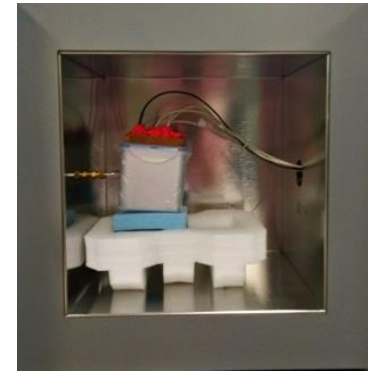

(b)
Gambar 2. (a) Cylinder mini chamber (b) Square mini chamber

Secara sederhana bentuk dan ukuran cylinder mini chamber dijabarkan pada Gambar 3. Ukuran dari chamber adalah sebagai berikut : diameter $(\mathrm{a})=2.96 \mathrm{~cm}$; panjang $(\mathrm{b})=22 \mathrm{~cm}$; diameter $(\mathrm{c})=26.2 \mathrm{~cm}$. Titik (a) terhubung dengan keluaran dari saturator dengan aliran gas sebesar $15 \mathrm{~L} / \mathrm{min}$. Titik (c) berada pada kondisi terbuka sehingga gas mengalir ke chamber utama. Hal tersebut bertujuan agar tekanan di dalam mini chamber dapat terkondisikan (Tistomo, Achmadi, \& Rifai, Characterization of KIM LIPI's Relative Humidity Standard, 2014). 


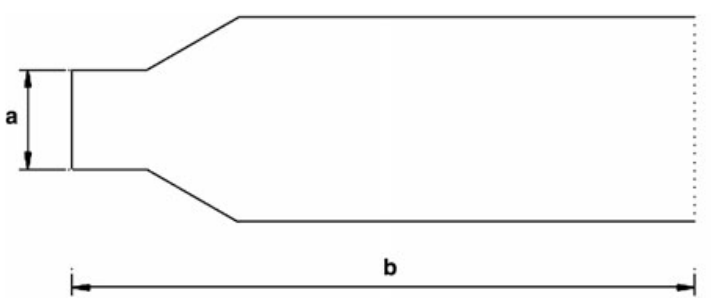

Gambar 3. Cylinder mini chamber

Sedangkan untuk square mini chamber dijabarkan pada gambar 4. Square mini chamber memiliki ukuran panjang, lebar dan tinggi berturut - turut sebesar $10,5 \mathrm{~cm}, 7 \mathrm{~cm}$ dan 11,5 $\mathrm{cm}$. Pada gambar terlihat terdapat 6 lubang di atas chamber yang berfungsi untuk menempatkan 2 buah RTD dan 4 buah DUT berupa probe termohigrometer DewK. Lubang a dan $\mathrm{b}$ memiliki diameter masing-masing $5 \mathrm{~mm}$. Lubang a terhubung dengan keluaran gas dari saturator. Dengan laju aliran keluaran dikondisikan sama dengan proses kalibrasi yang sudah berlangsung yaitu sebesar $15 \mathrm{~L} / \mathrm{min}$. Agar tekanan di dalam mini chamber yang tetutup tidak meningkat, maka lubang $b$ dibuat dengan tujuan agar gas dapat keluar dari chamber.

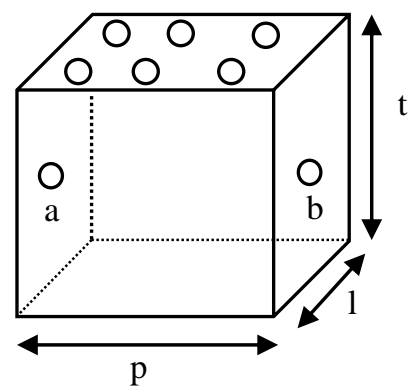

Gambar. 4. Square mini chamber

Selama kalibrasi berlangsung terdapat dua buah RTD yang digunakan yaitu RTD yang merupakan bawaan dari two-pressure humidity generator dan 1 RTD lain merk OMEGA yang terhubung ke indicator ASL F-16. Kedua RTD tersebut berfungsi untuk pengukuran ketidakseragaman suhu selama proses kalibrasi berlangsung. Perbedaan penempatan kedua sensor dapat dilihat pada Gambar 5.

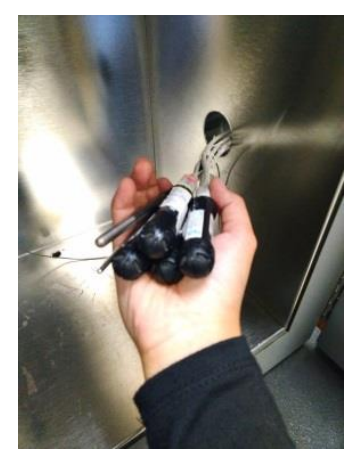

(a)

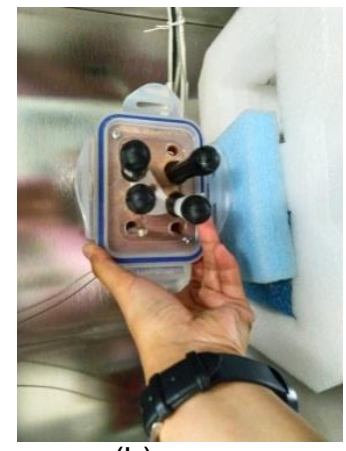

(b)
Gambar 5. Posisi penempatan RTD

Gambar 5(a) adalah posisi penempatan RTD pada cylinder mini chamber, dimana RTD dan DUT saling berdekatan satu dengan yang lainnya tanpa ada jarak. Sedangkan pada gambar 5(b) posisi RTD dan DUT pada square mini chamber terdapat jarak sehingga masingmasing sensor tidak saling bersentuhan.

\section{HASIL DAN PEMBAHASAN}

Telah dilakukan kalibrasi termohigrometer dengan menggunakan two-pressure humidity generator. Tabel 1 menunjukkan besarnya ketidkapastian pengukuran suhu dan kelembapan menggunakan dua buah mini chamber. Pengukuran dilakukan pada rentang ukur suhu $18 \sim 22^{\circ} \mathrm{C}$ dan rentang ukur kelembapan 45 65\%RH sehingga didapatkan besarnya nilai ketidakpastian suhu dan kelembapan seperti yang tertera pada tabel 1 .

Tabel 1 Ketidakpastian pengukuran dua mini chamber

\begin{tabular}{ccccc}
\hline & \multicolumn{2}{c}{ Square mini chamber } & \multicolumn{2}{c}{$\begin{array}{c}\text { Cylinder mini } \\
\text { chamber }\end{array}$} \\
\cline { 2 - 5 } & $\begin{array}{c}\text { Suhu } \\
\left({ }^{\circ} \mathrm{C}\right)\end{array}$ & $\begin{array}{c}\text { Kelembapan } \\
(\% \mathrm{RH})\end{array}$ & $\begin{array}{c}\text { Suhu } \\
\left({ }^{\circ} \mathrm{C}\right)\end{array}$ & $\begin{array}{c}\text { Kelembapan } \\
(\% \mathrm{RH})\end{array}$ \\
\hline $\begin{array}{c}\text { Probe } \\
1\end{array}$ & 0.08 & 0.46 & 0.08 & 0.48 \\
\hline $\begin{array}{c}\text { Probe } \\
2\end{array}$ & 0.08 & 0.46 & 0.08 & 0.50 \\
\hline $\begin{array}{c}\text { Probe } \\
3\end{array}$ & 0.08 & 0.46 & 0.08 & 0.56 \\
\hline $\begin{array}{c}\text { Probe } \\
4\end{array}$ & 0.08 & 0.47 & 0.08 & 0.46 \\
\hline
\end{tabular}

Dari data yang disajikan pada Tabel 1 dapat diketahui bahwa penggunaan square mini chamber menyajikan nilai ketidakpastian untuk kelembapan relatif yang lebih kecil dibandingkan dengan cylinder mini chamber. Perbedaan nilai yang diberikan berada pada rentang $0,01 \% \mathrm{RH}$ 
$0,1 \% R H$. Sedangkan untuk pengukuran suhu kedua mini chamber, besarnya nilai ketidakpastian yang didapatkan berada pada nilai sama besar.

Ketidakseragaman suhu dari chamber maupun mutual self heating dari masing-masing sensor tidak memberikan pengaruh yang besar terhadap hasil perhitungan ketidakpastian pada pengukuran ini. Hal tersebut mungkin saja dikarenakan kalibrasi dilakukan pada rentang ukur yang sempit yaitu pada rentang ukur suhu rentang ukur kalibrasi yang dilakukan pada $18 \sim 22^{\circ} \mathrm{C}$ dan rentang ukur kelembapan 45 65 $\% \mathrm{RH}$. Sama seperti penelitian sebelumnya dimana ketidakseragaman suhu yang didapatkan menggunakan cylinder mini chamber adalah sebesar $\pm 0,04^{\circ} \mathrm{C}$ (Tistomo, Achmadi, \& Rifai, 2014), nilai ketidakseragaman suhu yang didapatkan selama proses kalibrasi berlangsung menggunakan square mini chamber-pun menunjukkan hasil yang serupa yaitu $\pm 0,04^{\circ} \mathrm{C}$.

Selanjutnya selain proses kalibrasi yang sudah dilakukan dilakukan pengukuran suhu pada rentang ukur yang lebih lebar. Pengukuran suhu dilakukan pada tiga titik ukur yaitu $5^{\circ} \mathrm{C}$, $27^{\circ} \mathrm{C}$, dan $50^{\circ} \mathrm{C}$. Pengambilan data suhu dilakukan selama 30 menit dengan jarak waktu pengambilan 30 detik. Respon dari DUT selama pengukuran berlangsung disajikan pada gambar 6 s.d Gambar 8.

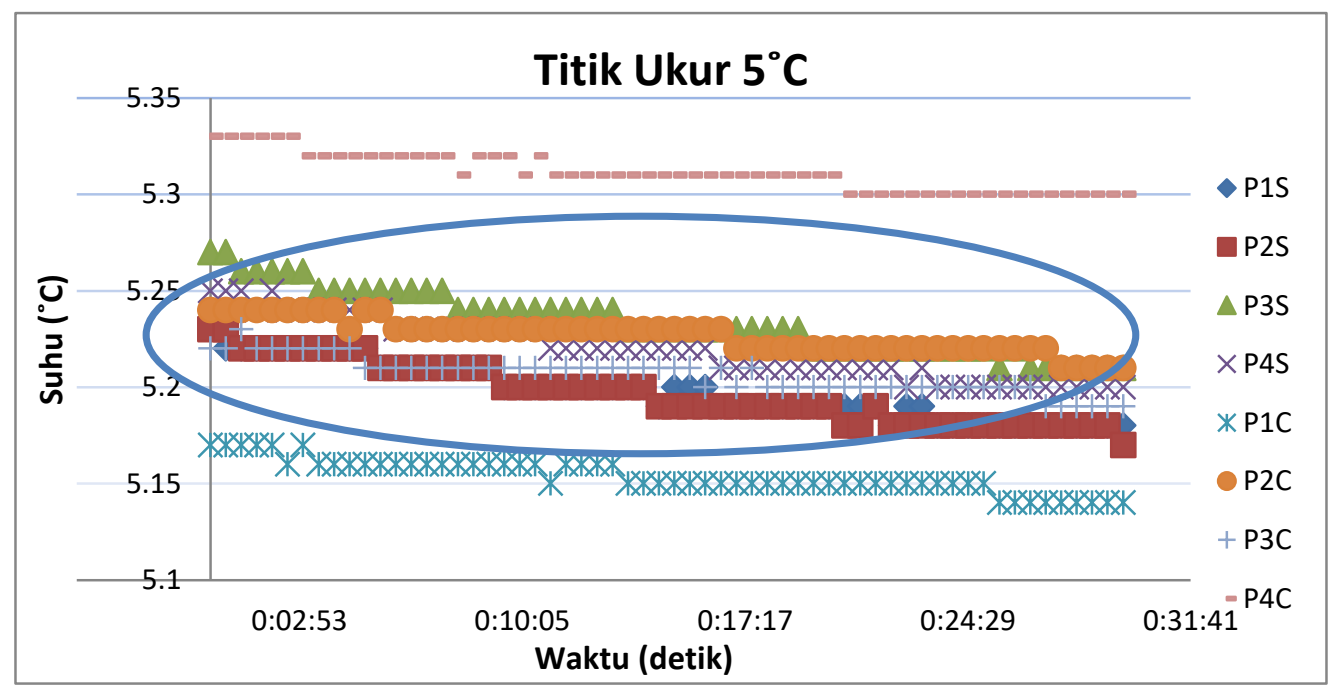

Gambar 6 Respon DUT pada titik ukur $5^{\circ} \mathrm{C}$

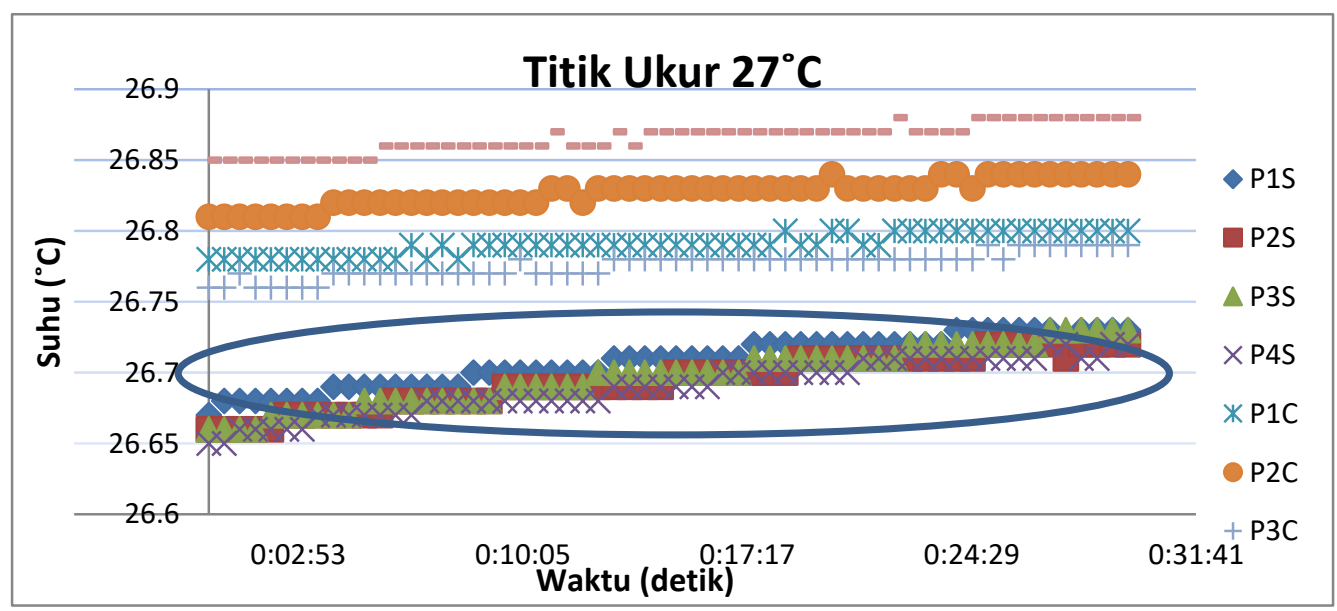

Gambar 7 Respon DUT pada titik ukur $27^{\circ} \mathrm{C}$ 


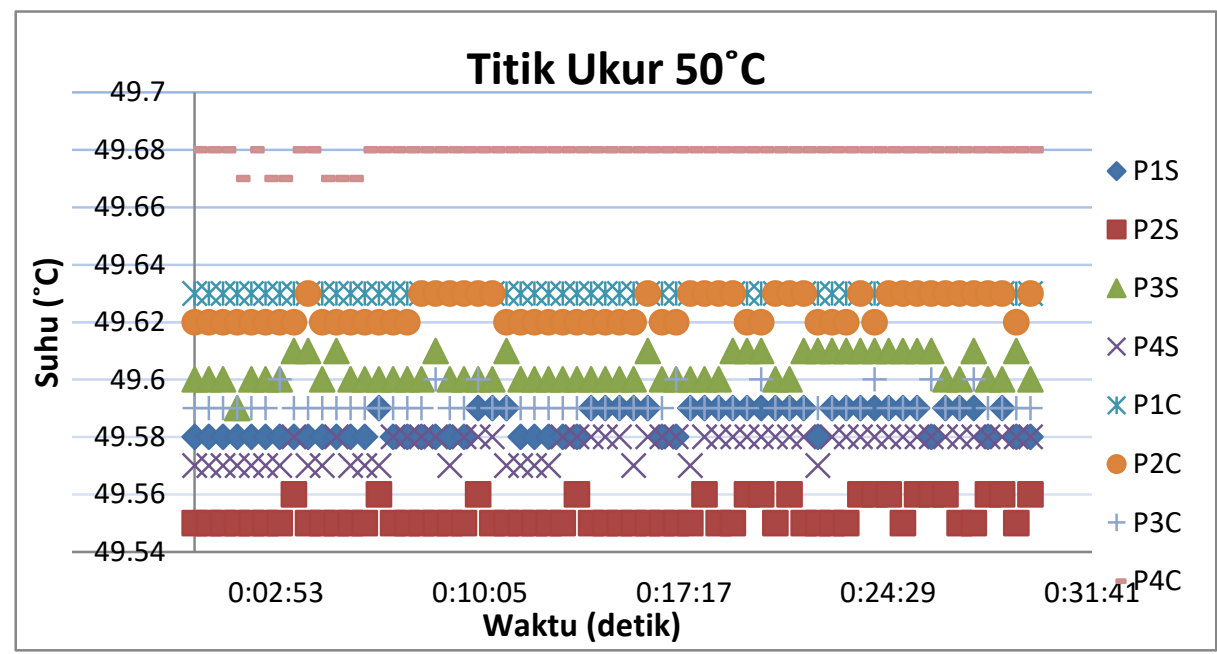

Gambar 8 Respon DUT pada titik ukur $50^{\circ} \mathrm{C}$

Gambar 6, Gambar 7 dan Gambar 8 menyajikan besarnya nilai suhu dari setiap DUT selama 30 menit. Kode P mengidentifikasi probe, angka (1-4) mengidentifikasi urutan dari probe dan kode S/C mengidentifikasi chamber yang digunakan, S untuk Square mini chamber dan C untuk cylinder mini chamber. Maka P1S perupakan probe 1 yang diukur menggunakan square mini chamber sedangkan P1C merupakan probe 1 yang dikur menggunakan cylincer mini chamber.

Dari data grafik yang disajikan yaitu pada gambar 6 dan gambar 7 dimana terdapat data berada dalam lingkaran biru, terlihat probe yang diukur dengan menggunakan square mini chamber menunjukkan nilai yang lebih presisi. Antara probe yang satu dengan yang lainnya menunjukkan pengukuran suhu pada nilai yang berdekatan baik pada titik ukur $5{ }^{\circ} \mathrm{C}, 27{ }^{\circ} \mathrm{C}$, maupun $50{ }^{\circ} \mathrm{C}$. Apabila dibandingkan dengan pengukuran suhu menggunakan cylinder mini chamber, nilai suhu yang terukur oleh masingmasing probe menunjukan nilai yang lebih beragam dengan rentang perbedaan pengukuran suhu hingga $0,2{ }^{\circ} \mathrm{C}$ pada titik ukur 5 ${ }^{\circ} \mathrm{C}$. Dengan demikian nilai yang terukur oleh probe pada pengukuran menggunakan square mini chamber menunjukkan nilai yang lebih presisi dibanding dengan cylinder mini chamber.

Koreksi penunjukan pengukuran suhu setiap probe dibandingkan dengan standar yang digunakan disajikan pada table 2. Pengukuran pada cylinder mini chamber menunjukkan nilai koreksi yang lebih besar. Sehingga dapat disimpulkan bahwa square mini chamber menawarkan nilai pengukuran dengan nilai akurasi yang lebih baik.
Tabel 2. Koreksi terhadap standar

\begin{tabular}{cccccccccc}
\hline \multirow{2}{*}{$\begin{array}{c}\text { Titik } \\
\text { Ukur }\end{array}$} & \multicolumn{3}{c}{ Square mini Chamber } & \multicolumn{5}{c}{ Cylinder mini chamber } \\
\cline { 2 - 9 } & P1 & P2 & P3 & P4 & P1 & P2 & P3 & P4 \\
\hline $5^{\circ} \mathrm{C}$ & 0.20 & 0.21 & 0.17 & 0.18 & 0.34 & 0.27 & 0.29 & 0.18 \\
\hline $27^{\circ} \mathrm{C}$ & 0.17 & 0.19 & 0.18 & 0.19 & 0.23 & 0.20 & 0.25 & 0.16 \\
\hline $50^{\circ} \mathrm{C}$ & 0.11 & 0.14 & 0.09 & 0.12 & 0.17 & 0.17 & 0.21 & 0.12 \\
\hline
\end{tabular}

Dari penjabaran pada paragraph sebelumnya dapat dikatakan bahwa terdapat pengaruh dari mutual self heating selama proses pengukuran berlangsung. Pada cylinder mini chamber dimana tidak terdapat jarak antar probe, nilai presisi dan akurasi yang terukur dari setiap probe menunjukkan nilai tidak lebih baik dibanding dengan pengukuran yang diberi jarak antar probe.

Apabila pada proses kalibrasi yang dilakukan pada rentang ukur $18 \sim 22^{\circ} \mathrm{C}$ tidak menunjukkan perbedaan nilai ketidakseragaman suhu dari chamber, maka pada Gambar 9 menunjukkan adanya perbedaan dari ketidakseragaman chamber selama pengukuran pada rentang yang lebih lebar. Dari grafik terlihat pada suhu $50^{\circ} \mathrm{C}$ terdapat perbedaan yang cukup signifikan pada kedua chamber. Besarnya nilai ketidakseragaman suhu pada square mini chamber menunjukkan nilai yang jauh lebih kecil pada suhu $50^{\circ} \mathrm{C}$. Selain itu terlihat semakin tinggi titik ukur suhu, maka nilai ketidakseragaman yang didapatkan juga semakin besar. Nilai ketidakseragaman ini merupakan salah satu komponen penyumbang ketidakpastian pada 
pengukuran suhu dengan presentase yang besar, yaitu sekitar $\pm 40 \%$ dari ketidakpastian gabungan. Lebih jauh lagi, besarnya ketidaksergaman suhu selama proses kalibrasi ini juga berpengaruh pada perhitungan ketidakpastian dari kelembapan relative .

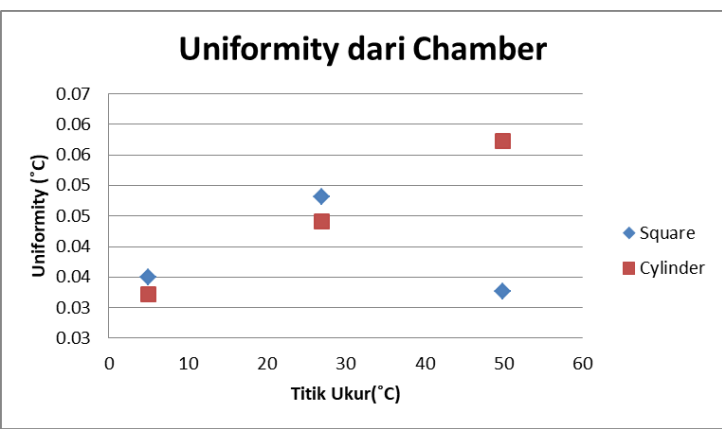

Gambar 9. Ketidakseragaman suhu di dalam chamber

Terdapat perbedaan nilai dari pengukuran menggunakan dua buah mini chamber. Baik evaluasi dari kepresisian dan akurasi dari DUT yang dikalibrasi maupun dari ketidkaseragaman suhu di dalam chamber. Perbedaan nilai yang didapatkan dari kedua pengukuran kemudian dievaluasi menggunakan En Number, dimana perhitungan statisitik tersebut digunakan untuk menegtahui apakah kedua metode yang digunakan masih memenuhi satu dengan yang lainnya. Dengan menggunakan persamaan 5 dilakukan perhitungan terhadap En Number membandingkan kedua metode.

$E_{n}=\frac{x-X}{\sqrt{U_{x}^{2}+U_{X}^{2}}}$

Dimana $U_{x}$ dan $U_{X}$ adalah ketidakpastian gabungan dari masing-masing metode pengukuran serta $x$ dan $X$ adalah koreksi pengukuran. (Mann \& Brookman, 2011). Dari perhitungan tersebut didapatkan nilai En Number terbesar dari setiap probe adalah $\left|E_{n}\right|=0,9$. Dengan nilai $\left|E_{n}\right|<1$, maka dapat dikatakan bahwa kedua metode, baik menggunakan cylinder mini chamber maupun square mini chamber, dapat digunakan. Namun untuk menjamin bahwa nilai presisi dan akurasi dari DUT yang dikalibrasi mendapatkan hasil yang baik, maka penggunaan square mini chamber dapat dipilih dalam proses kalibrasi probe thermohygrometer

\section{KESIMPULAN}

Dari penjabaran hasil yang didapatkan dapat disimpulkan bahwa semakin tinggi titik ukur suhu yang digunakan dalam proses kalibrasi maka dapat mempengaruhi nilai ketidakseragaman didalam chamber. Apabila kedua chamber dibandingkan, maka didapati bahwa respon DUT selama proses pengukuran menggunakan square mini chamber menunjukkan nilai yang lebih presisi dan akurat bila dibandingkan dengan cylinder mini chamber. Hal tersebut mungkin saja dikarenakan adanya pengaruh mutual self heating dari masing-masing DUT.

Evaluasi lain dengan menggunakan metode statistic En Number menunjukkan bahwa nilai pengukuran yang didapatkan dari kedua mini chamber masih dapat digunakan. Mengacu pada ISO/IEC 17025 mengenai validasi metode untuk menjamin mutu hasil kalibrasi, dapat disimpulkan bahwa hasil pengukuran yang menggunakan kedua mini chamber valid sehingga keduanya dapat digunakan.

\section{UCAPAN TERIMA KASIH}

Ucapan terimakasih kepada semua pihak yang ikut berperan terutama kepada Kepala Subdirektorat SNSU Suhu yang telah mengizinkan digunakannya peralatan kalibrasi primer thermohigrometer sehingga penelitian ini dapat terselesaikan dengan baik

\section{DAFTAR PUSTAKA}

Doiron, T., \& Beers, J. (1995). The Gauge Block Handbook. Gaithersburg: NIST.

EI-Galil, D. M., \& Mahmoud, E. (2016). NIS TwoPressure Humidity Generator. International Journal Metrology Quality Engineering (IJMQE).

Fluke. (2011). Technical Data 1620A DewK Thermo Higrometer. Everett: Fluke Calibration.

Hardy, B. (1998). Chamber Temperature Uniformity of The Thunder Scientific Model 2500 Two Pressure Humidity Generator. Albuquerque: Thunder Scientific Corporation.

Hardy, B. (1998). ITS-90 Formulations for Vapor Pressure, Frost Point Temperature, Dew Point Temperature and Endachement Factors in the Range - 100 to +100 . 
Third International Symposium on Humidity and Moisture (pp. 214 - 222). London: NPL.

Haryadi, G. D. (2006). Pengaruh Suhu Tempering Terhada Kekerasan, Kekuatan Tarik, dan Struktur Mikro pada Baja K-460. ROTASI.

Hasegawa, S., \& Little, J. W. (1977). The NBS Two Pressure Humidity Generator, Mark 2. JOURNAL OF RESEARCH of the Notional Bureau of Standards-A. Physics and Chemistry, 81-88.

Heinonen, M. (2018). Advance Methods for Humidity Calibration and Uncertainty. Taastrup: VTT Mikes.

IEC. (2017). IEC 60942. Geneva: IEC.

Mann, I., \& Brookman, B. (2011). Selection, Use and Intepretation Of Prficienty Testing Schemes. EURACHEM.

Moris, E. C. (1992). Humidity Measurement, Temperature Measurement Course. CSIRO Division of Applied Science.

Rifai, I. A., \& Tistomo, A. S. (2012). Evaluasi Calibration Measurement Capability Two-Pressure Humidity Generator Untuk Pelaksanaan Kalibrasi Thermohygrometer. PPI KIM Ke-32 (pp. 168-180). Tangerang Selatan: Pusat Penelitian Kalibrasi, Instrumentasi dan Metrologi LIPI.

Salsbury, J. (2018). Temperature and Dimentional Measurement. Mitutoyo Corporation.

Taylor, B. N., \& Kuyyat, C. E. (1994). Guidelines for Evaluating and Expressing the Uncertainty of NIST Measurement Result. NIST .

Thunder Scientific. (2018). Model 2500 Benchtop / Mobile Two-Pressure Humidity Generator. Wyoming: Thunder Scientific.

Thunder Scientific Corporation. (2007). Operating and Manual Benchtop TwoPressure Humidity Generators Series 2500. Wyoming: Thunder Scientific Corporation.

Tistomo, A. S. (2009). Karakterisasi Kestabilan Tekanan Saturator Pada High Humid Two Pressure Humidity Generator KIM LIPI. PPI KIM 34 (pp. 145-156). Jakarta: Pusat Penelitian Kalibrasi Instrumentasi dan Metrologi LIPI.

Tistomo, A. S., Achmadi, A., \& Rifai, I. A. (2014). Characterization of KIM LIPI's Relative Humidity Standard. MAPAN-Journal of Metrology Society of India, 51-55.
Walker, R., \& Cordner, A. (2006). Temeprature and Relative Humidity Calibration System. NCSL International Workshop and Symposium. Utah: NCSL.

Wexler, A., \& Daniels, R. (1952). PressureHumidity Apparatus. Journal of Research of The National Bureau of Standards, 269-274. 
